\title{
Publication Rates of Presentations at Annual Scientific Meetings of the Turkish Neurosurgical Society
} \author{
Deniz KONYA3 , Turker KILIC ${ }^{3}$ \\ ${ }^{1}$ University of California, Department of Orthopedic Surgery-Spine Center, San Francisco, CA, USA \\ ${ }^{2}$ Bismil State Hospital, Neurosurgery Clinic, Diyarbakır, Turkey \\ ${ }^{3}$ Bahceşehir University, Medical Faculty, Department of Neurosurgery, Istanbul, Turkey \\ ${ }^{*}$ Murat Sakir EKSI and Sumeyye Coruh KAPLAN contributed equally to the article.
}

Murat Sakir EKSI ${ }^{1 *}$, Sumeyye Coruh KAPLAN²* ${ }^{*}$, Baran YILMAZ $^{3}$, Akin AKAKIN $^{3}$, Zafer Orkun TOKTAS ${ }^{3}$,

\section{ABSTRACT}

AIM: National and international society meetings are suitable mediums at which diverse research topics from basic, clinical and translational sciences can be presented to an audience of peers. In this study, our purpose was to evaluate publication rates of presentations in the last recent four years' annual scientific meetings of Turkish Neurosurgical Society (TNS).

MATERIAL and METHODS: Abstracts of both podium and poster presentations were retrieved from the congress booklets of TNS. Study timeline included TNS annual scientific meetings of 2011, 2012, 2013, and 2014. Abstract titles and author names of the abstracts were searched in Pubmed/MEDLINE and Google Scholar databases.

RESULTS: In total, 3105 presentations to an audience took place in the annual scientific meetings of TNS organized between 2011 and 2014. Acceptance rate of these studies by peer-reviewed scientific journals was 326 (10.5\%). In sub-analysis, there were 2408 electronic posters (148 accepted, 6.1\%), 195 poster presentations with discussion (44 accepted, $22.6 \%$ ), and 502 podium presentations (134 accepted, 26.7\%).

CONCLUSION: Acceptance rate of podium presentations in annual scientific meeting of TNS is at comparable levels with similar organizations on the world. However, the rate is lower for poster presentations.

KEYWORDS: Abstract, Podium presentation, Poster presentation, Publication, Peer-review

\section{INTRODUCTION}

$\mathrm{N}$ ational and international society meetings are suitable mediums at which diverse research topics from basic, clinical and translational sciences can be presented to an audience of peers. Presentations are made in oral or poster form according to preliminary selection processes. This provides the opportunity to discuss the study results and revise them before submission to peer-reviewed journals. The Turkish Neurosurgical Society (TNS) is the prominent governing body for neurosurgeons in Turkey (24). Scientific meetings have been held yearly for the past 28 years and are becoming more international every year.

In this study, our purpose was to evaluate publication rates of the presentations in the last four years' annual scientific meetings of TNS.

\section{MATERIAL and METHODS}

Abstracts of both podium and poster presentations were retrieved from the congress booklets of TNS. The study timeline 
included TNS annual scientific meetings of 2011, 2012, 2013, and 2014. Abstract titles and author names of the abstracts were searched in Pubmed/MEDLINE and Google Scholar databases. If search did not give a result for the abstract, it was assumed that the study had not been published in a peerreviewed journal. Similar abstract titles with similar authors in scientific databases have been accepted as 'published article'.

\section{RESULTS}

In 2011, 469 electronic posters were presented and 75 poster presentations with discussion and 113 podium presentations were held during the annual scientific meeting of TNS. Of these presentations, 124 (18.8\%) were published in peer-reviewed scientific journals. If we sub-analyze this percentage, we observe that $49(10.4 \%)$ of the electronic posters, 27 (36\%) of the poster presentations with discussion, and $48(42.4 \%)$ of podium presentations were published. In the annual meeting organized in 2012, there were 773 presentations in total. Five-hundred-eighty-five of the presentations were electronic posters, 60 were poster presentations with discussion and 128 were podium presentations. Publication percentage of the meeting presentations was $11.8 \%$ (91/773). Forty-four $(7.5 \%)$ of the electronic posters, $11(18.3 \%)$ of the poster presentations with discussion, and $36(28.1 \%)$ of the podium presentations were accepted in peer-reviewed journals. The total number of presentations was 781 in 2013, of which 67 (8.6\%) were published. There were 621 electronic posters, 30 poster presentations with discussion, and 130 podium presentations in the meeting. Thirty-four $(5.5 \%)$ of the electronic posters, $5(16.6 \%)$ of the poster presentations with discussion, and $28(21.5 \%)$ of the podium presentations were accepted as publications. In 2014, there were 894 presentations, of which 733 were electronic posters, 30 were poster presentations with discussion, and 131 were podium presentations. Fortyfour of the abstracts were accepted (4.9\%). Acceptance rates were $21(2.8 \%), 1(3.3 \%)$, and 22 (16.8\%) respectively. In total, 3105 presentations were given to audience in the annual scientific meetings of TNS organized between 2011 and 2014. Acceptance rate of these studies by peer-reviewed scientific journals was 326 (10.5\%). In sub-analysis, there were 2408 electronic posters (148 accepted, 6.1\%), 195 poster presentations with discussion (44 accepted, 22.6\%), and 502 podium presentations (134 accepted, 26.7\%) (Table I).

Major peer-reviewed journals, which published abstracts presented at the annual scientific meetings of TNS between 2011 and 2014 were Turkish Neurosurgery, Acta Neurochirurgica, Child's Nervous System, Journal of Neurological SciencesTurkish, Journal of Neurosurgery, Clinical Neurology and Neurosurgery, Türk Nöroşirurji Dergisi, Neurosurgery Quarterly, Cumhuriyet Medical Journal, and Journal of Neurological Surgery (Figures 1, 2).

\section{DISCUSSION}

Scientific studies start with a question that has emerged after analyzing previous information, which leads to defining a hypothesis, clarifying materials and methods, collecting data, analyzing the data and producing final new information born from the previous one which can be disseminated via publications (19). The scientific meetings are the most available areas at which results can be presented to colleagues before submission to peer-reviewed journals. Besides, new ideas and questions may emerge in the discussions $(4,19)$. Results presented at scientific meetings find ground by being applied to clinical practice (4). Before becoming an oral or a poster presentation in the meeting, a through peer-review process is handled by a scientific board of the congress which is composed of renowned scientists and clinicians of their fields (19).

Publication rates of different subspecialty scientific meetings have been analyzed to clarify the quality of the meetings. Publication rates of $11-78 \%$ were mentioned in these studies $(1-16,20,22,23,25,26)$. Specifically, publication rate of presentations of the 1996 Annual Meeting of the American Academy of Orthopaedic Surgeons was $34 \%$ (1). Overall rate of publication of the presentations held in NASS (North American Spine Society), SRS (Scoliosis Research Society), and ISSLS (The International Society for the Study of the Lumbar Spine) was $43.5 \%$. Separately the rates were $40 \%$, $47 \%$ and $45 \%$, respectively (25). The publications rate was found to be as high as $68 \%$ for the presentations at the Society for Gynecologic Investigation in a 9-year period (1990-1999) but it was also mentioned that most of the publications had

Table I: Publication Rates According to Presentation Type and Presentation Year in the Annual Scientific Meetings of Turkish Neurosurgical Society

\begin{tabular}{|c|c|c|c|c|c|c|}
\hline Year & $\begin{array}{l}\text { Number of } \\
\text { electronic } \\
\text { posters }\end{array}$ & $\begin{array}{c}\text { Electronic } \\
\text { posters } \\
\text { published (\%) }\end{array}$ & $\begin{array}{c}\text { Number of poster } \\
\text { presentations with } \\
\text { discussion }\end{array}$ & $\begin{array}{c}\text { Poster presentations } \\
\text { with discussion } \\
\text { published }(\%)\end{array}$ & $\begin{array}{c}\text { Number } \\
\text { of podium } \\
\text { presentations }\end{array}$ & $\begin{array}{c}\text { Podium } \\
\text { presentations } \\
\text { published (\%) }\end{array}$ \\
\hline 2012 & 585 & 7.5 & 60 & 18.3 & 128 & 28.1 \\
\hline 2013 & 621 & 5.5 & 30 & 16.6 & 130 & 21.5 \\
\hline Total & 2408 & 6.1 & 195 & 22.6 & 502 & 26.7 \\
\hline
\end{tabular}



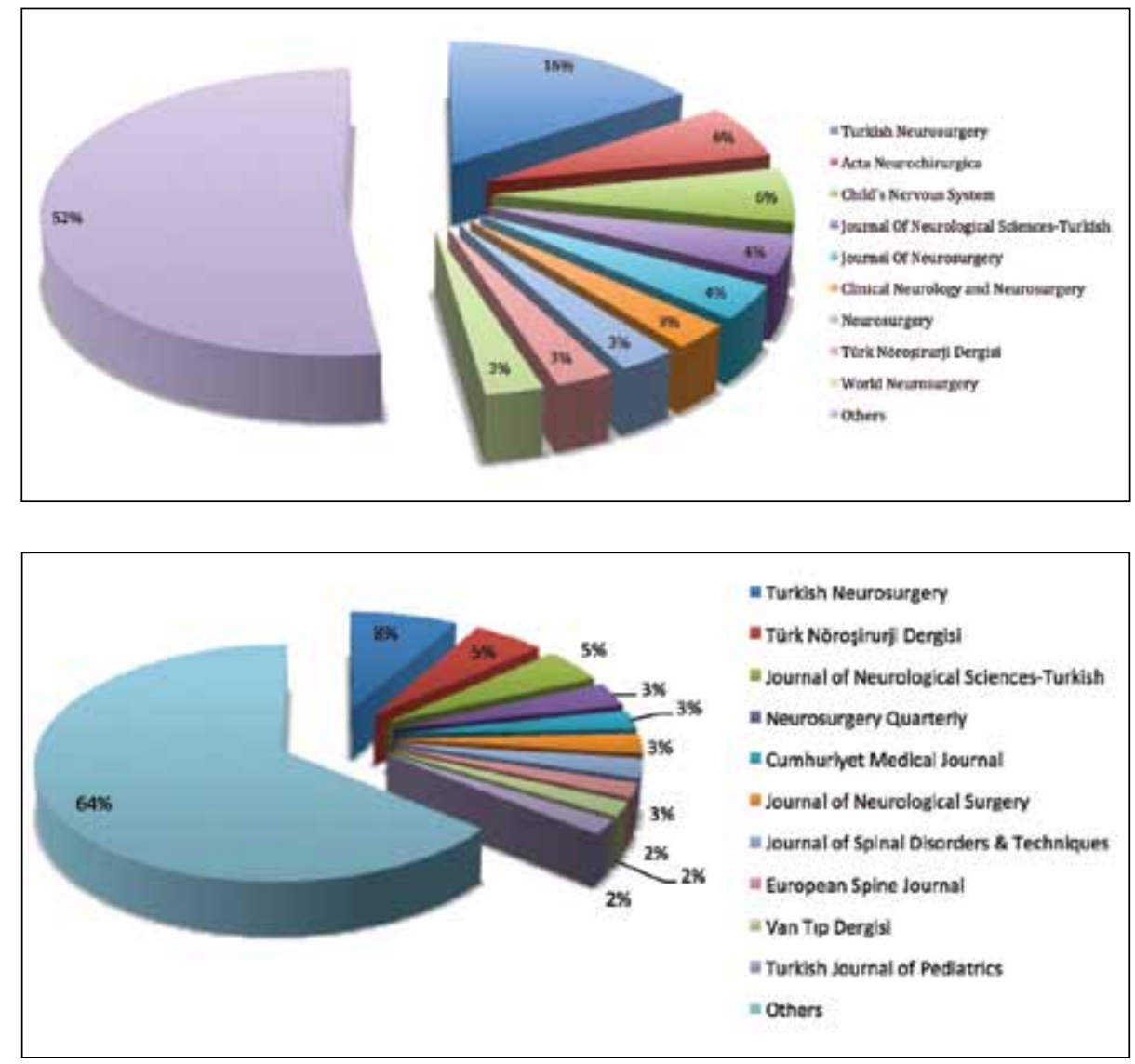

Figure 1: Acceptance rates of podium presentations and poster presentations with discussion in peer-reviewed scientific journals.
Figure 2: Acceptance rates of electronic posters in peer-reviewed scientific journals. been published in group 3 journals (7). Publication rates for the presentations at the American Urological Association Annual Meeting were 59\% (podium presentations), 55\% (poster presentations), $55 \%$ (unmoderated poster presentations), and $42 \%$ (video presentations). Despite the high publication rates, overall journal impact factors for accepted manuscripts were at a modest level (10). The overall rate for presentations at the 2007 and 2010 Canadian Association of Radiation Oncology Meeting was $51.2 \%$ and published about 1.5 years following the presentations (14). Patel et al. (19) analyzed the publication rates of abstracts presented at the American Association of Neurological Surgeons (AANS) and the Congress of Neurological Surgeons (CNS), which are two big neurosurgical societies in the U.S.A. They stated that publication rates were $30.91-33.95 \%$ and $29.79-35.40 \%$, respectively. Acceptance rate ranged from $4.9 \%$ to $18.8 \%$ in our study, being lowest in the last year and highest in 2011. As the peer review and revision process takes time, we expect more studies to be accepted in later years. It was also found that overall time for an abstract to be indexed in Medline/Pubmed is 5 years and $90 \%$ of the abstracts presented at a meeting get published within 4 years $(4,20-22)$. So, we compared 2011 TNS annual meeting results with 2003 AANS and CNS annual meeting results (both are starting points for the two studies) to enable a healthier conclusion. Acceptance rates for the abstracts presented on the podium were similar (42.4\% in TNS, $42.02 \%$ in AANS, and $42.80 \%$ in CNS). However, acceptance rate for poster presentations (combination of electronic posters and poster presentations with discussion) in TNS (13.9\%) were lower than the acceptance rate of the ones presented in AANS (32.14\%) and CNS (28.73\%) (19). Acceptance rate for podium presentations of TNS were higher than all kinds of poster presentations, which is due to vigorous election process for podium presentations $(p<0.01)$. Another point is that the vast majority of poster presentations were case series or case reports, which have evidence levels of 4 and 5 , respectively. Most scientific journals have recently turned to accepting manuscripts with higher levels of evidence. In an analysis performed by Scherer et al., the most common reasons for non-publication of abstracts were 'lack of time and resources' (23). Although, acceptance rates for abstracts with positive results were comparable to abstracts with negative results, there is a preconceived idea in authors' minds that abstracts with negative results would be rejected by scientific journals $(17,18)$.

The journals that accepted abstracts presented at the 20112014 annual scientific meeting of TNS were also analyzed. The three leading journals were Turkish Neurosurgery, Acta Neurochirurgica, and Clinical Neurology and Neurosurgery. Our limitation in this study was that we conducted our study using Pubmed/Medline and Google Scholar databases, so the abstracts that were accepted by scientific journals and not indexed in these 2 big databases may have been missed. 


\section{CONCLUSION}

The acceptance rate of podium presentations in annual scientific meeting of TNS is at comparable levels with similar organizations in the world. However, the rate is lower for poster presentations. To enhance the acceptance rate of the abstracts, the authors should spare time and resources to their projects and insist on what they have found even if the results are negative.

\section{ACKNOWLEDGMENT}

Murat Şakir EKSI M.D. was supported by a grant from TÜBITAK (The Scientific and Technological Research Council of Turkey), Grant number: 1059B191400255.

\section{- REFERENCES}

1. Bhandari M, Devereaux PJ, Guyatt GH, Cook DJ, Swiontkowski MF, Sprague S, Schemitsch EH: An observational study of orthopaedic abstracts and subsequent full-text publications. J Bone Joint Surg Am 84-A:615-621, 2002

2. Byerly WG, Rheney CC, Connelly JF, Verzino KC: Publication rates of abstracts from two pharmacy meetings. Ann Pharmacother 34:1123-1127, 2000

3. Daluiski A, Kuhns CA, Jackson KR, Lieberman JR: Publication rate of abstracts presented at the annual meeting of the Orthopaedic Research Society. J Orthop Res 16:645-649, 1998

4. DeMola PM, Hill DL, Rogers K, Abboud JA: Publication rate of abstracts presented at the shoulder and elbow session of the American Academy of Orthopaedic Surgery. Clin Orthop Relat Res 467:1629-1633, 2009

5. Donegan DJ, Kim TW, Lee GC: Publication rates of presentations at an annual meeting of the American Academy of Orthopaedic Surgeons. Clin Orthop Relat Res 468:14281435, 2010

6. Easterbrook PJ, Berlin JA, Gopalan R, Matthews DR: Publication bias in clinical research. Lancet 337:867-872, 1991

7. Gandhi SG, Gilbert WM: Society of Gynecologic Investigation: What gets published? J Soc Gynecol Investig 11:562-565, 2004

8. Gorman RL, Oderda GM: Publication of presented abstracts at annual scientific meetings: A measure of quality? Vet Hum Toxicol 32:470-472, 1990

9. Hamlet WP, Fletcher A, Meals RA: Publication patterns of papers presented at the Annual Meeting of The American Academy of Orthopaedic Surgeons. J Bone Joint Surg Am 79:1138-1143, 1997

10. Hoag CC, Elterman DS, Macneily AE: Abstracts presented at the American Urological Association Annual Meeting: Determinants of subsequent peer reviewed publication. J Urol 176:2624-2629; discussion 2629, 2006
11. Jackson KR, Daluiski A, Kay RM: Publication of abstracts submitted to the annual meeting of the Pediatric Orthopaedic Society of North America. J Pediatr Orthop 20:2-6, 2000

12. Jasko JJ, Wood JH, Schwartz HS: Publication rates of abstracts presented at Annual Musculoskeletal Tumor Society Meetings. Clin Orthop Relat Res:98-103, 2003

13. Juzych MS, Shin DH, Coffey JB, Parrow KA, Tsai CS, Briggs KS: Pattern of publication of ophthalmic abstracts in peerreviewed journals. Ophthalmology 98:553-556, 1991

14. Meissner A, Delouya G, Marcovitch D, Donath D, Taussky D: Publication rates of abstracts presented at the 2007 and 2010 Canadian Association of Radiation Oncology meetings. Curr Oncol 21:e250-254, 2014

15. Murrey DB, Wright RW, Seiler JG, 3rd, Day TE, Schwartz HS: Publication rates of abstracts presented at the 1993 annual Academy meeting. Clin Orthop Relat Res:247-253, 1999

16. Nguyen V, Tornetta P 3rd, Bkaric M : Publication rates for the scientific sessions of the OTA. Orthopaedic Trauma Association. J Orthop Trauma 12:457-459, 1998

17. Okike K, Kocher MS, Mehlman CT, Heckman JD, Bhandari M: Publication bias in orthopaedic research: An analysis of scientific factors associated with publication in the Journal of Bone and Joint Surgery (American Volume). J Bone Joint Surg Am 90:595-601, 2008

18. Olson CM, Rennie D, Cook D, Dickersin K, Flanagin A, Hogan JW, Zhu Q, Reiling J, Pace B: Publication bias in editorial decision making. JAMA 287:2825-2828, 2002

19. Patel AJ, Cherian J, Fox BD, Whitehead WE, Curry DJ, Luerssen TG, Jea A: Publication patterns of oral and poster presentations at the annual meetings of the Congress of Neurological Surgeons and the American Association of Neurological Surgeons. J Neurosurg 115:1258-1261, 2011

20. Riordan FA: Do presenters to paediatric meetings get their work published? Arch Dis Child 83:524-526, 2000

21. Roy D, Sankar V, Hughes JP, Jones A, Fenton JE: Publication rates of scientific papers presented at the Otorhinolarygological Research Society meetings. Clin Otolaryngol Allied Sci 26:253-256, 2001

22. Scherer RW, Dickersin K, Langenberg P: Full publication of results initially presented in abstracts. A meta-analysis. JAMA 272:158-162, 1994

23. Scherer RW, Ugarte-Gil C, Schmucker C, Meerpohl JJ: Authors report lack of time as main reason for unpublished research presented at biomedical conferences: A systematic review. J Clin Epidemiol 68(7):803-810, 2015

24. Solaroglu I, Acar F, Bavbek M, Ture U, Beskonakli E: The history of neurosurgery in Anatolia and Turkey: The Turkish Neurosurgical Society. World Neurosurg 79:16-24, 2013

25. Wang JC, Yoo S, Delamarter RB: The publication rates of presentations at major Spine Specialty Society meetings (NASS, SRS, ISSLS). Spine (Phila Pa 1976) 24:425-427, 1999

26. Yentis SM, Campbell FA, Lerman J: Publication of abstracts presented at anaesthesia meetings. Can J Anaesth 40:632634,1993 